\title{
SASK METHOD FOR TESTING HYDRAULIC CONDUCTIVITY OF SOILS BY FLAT DILATOMETER (DMT)
}

\author{
KAZIMIERZ GARBULEWSKi, STANISŁaW ŻAKOWICZ, \\ SiMON RABARIJOELY, ANNA ŁADA \\ Warsaw University of Life Sciences, Department of Geotechnical Engineering, \\ ul. Nowoursynowska 159, 02-776 Warsaw, Poland.
}

\begin{abstract}
DMT is one of the most popular methods of determining soil parameters needed to design a safe construction. Apart from the basic outcome parameter obtained from DMT measurements hydraulic conductivity $(k)$ can be determined, previously proposed DMTA and DMTC methods were modified. The basic idea of the method is that the return of the deformed membrane is due to soil and water pressure. In the proposed SASK method the hydraulic conductivity of the soil is determined by measuring time-varying pressures $A$ and $C$. Research has been performed at the experimental site of the Department of Geotechnical Engineering, WULS. In the paper, the assumptions of the new method for determining the hydraulic conductivity $k$ are presented. The proposed method allows us to determine a reliable value for the hydraulic conductivity of clay soils. Using this method, the value of hydraulic conductivity $\left(k=5,47 * 10^{-11}\right)$ is similar to the results of BAT, DMTA and laboratory measurements.
\end{abstract}

\section{LIST OF SYMBOLS}

$A$ - first pressure reading, which allows concave membrane to be in contact with the ground,

$C$ - third pressure reading that occurs during the return of the deformed membrane of $1.1 \mathrm{~mm}$,

$k \quad-$ hydraulic conductivity,

$p_{0} \quad-$ corrected first reading,

$p_{1}-$ corrected second reading,

$p_{2}-$ "closing pressure" $C$ corrected for membrane stiffness,

$p_{c}-$ dissipation of pressure $C$,

$p_{\text {flex }}-$ pressure at the inflection point,

$T_{\text {flex }}-$ inflection time on $A$ values curve,

$c_{h}-$ coefficient of horizontal consolidation,

$k_{h}$ - coefficient of horizontal hydraulic conductivity,

$a$ - dilatometer calibration coefficient,

$\gamma_{w}-$ water unit weight,

$M_{h}-$ soil compressibility modulus,

$Q$ - volume of water flow equal to the volume of a section of a sphere formed from the deformed membrane,

$Q_{k} \quad-\quad$ volume of sphere segment,

$l \quad-$ average range of soil involved in the flow of water,

$t_{2} \quad$ - time of water flow,

$R \quad-$ radius of the sphere,

$r \quad-\quad$ radius of the membrane, 


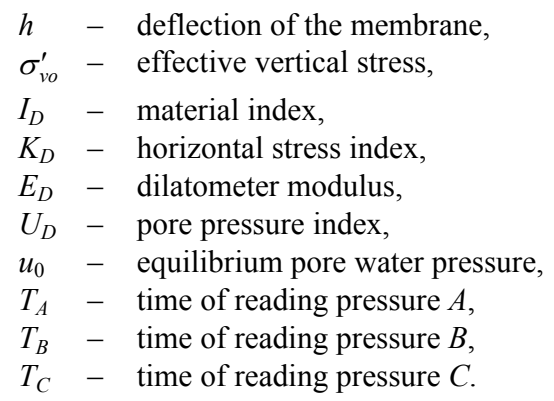

\section{INTRODUCTION}

Probings with Marchetti dilatometer (DMT) along with CPTU are included to standard tests commonly used in the assessment of geotechnical conditions of designed structures [2], [8], [9]. DMT test allows us to determine not only the standard soil parameters - strength and deformation, but also the hydraulic parameters needed for the design of hydraulic structures and for assessment of the environmental impact of buildings. The key parameter in the hydraulic design and environmental assessment of the soil-water conditions is coefficient of permeability $k$ commonly called hydraulic conductivity, for which two methods of determination according to DMT test were proposed: DMTC [10], [4], [5] and DMTA method [7]. One of the achievements of comprehensive research with dilatometer DMT application for fine-grained soils conducted in the Department of Geotechnical Engineering, Warsaw University of Life Sciences (WULS) is the development of the rules for the interpretation of data to determine the hydraulic conductivity. In the proposed method, the hydraulic conductivity of the soil is determined by measuring with dilatometer time-varying pressures $A$ and $C$. The value of $A$ is the pressure which allows the membrane to be in contact with the soil. The value of $C$ is the pressure that occurs during the return of the deformed membrane of $1.1 \mathrm{~mm}$ in the direction of the surrounding ground to the plane of the blade (Fig. 1). The proposed method for determining hydraulic permeability assumes that the return to the position of the deformed membrane to plane blade is thrust through the groundwater flowing from the surrounding fully saturated ground. The stream of groundwater flow depends on the geometry of the membrane deflection and time.

In the paper, the assumptions of the new method for determining the hydraulic conductivity $k$ are presented, as well as justification, research methodology and test results of clay soils at the experimental site of the Department of Geotechnical Engineering, WULS. The results of DMT tests comparing the BAT system lead to the conclusion that using the proposed method one can determine the correct values of hydraulic conductivity of clays. 
a)

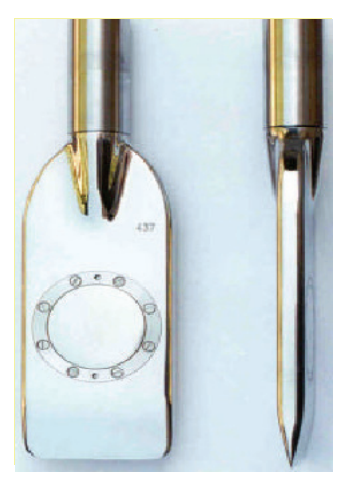

b)

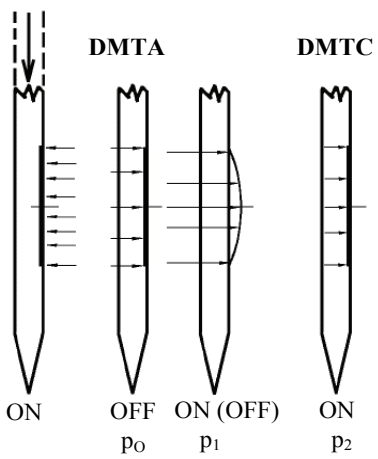

Fig. 1. View of device (a) and principles (b) of flat dilatometer tests (DMT)

\section{METHOD PROPOSED}

In the proposed SASK method to determine the hydraulic conductivity of the soil measured by DMT time-varying pressures $A$ or $C$ are used. The $A$ is the pressure, which allows concave membrane to be in contact with the ground while pressing the membrane into the surrounding soil. From the distribution of values of $A T_{\text {flex }}$ can be determined, following the assumption of Marchetti and Totani [7] in DMTA method that it is the time at which on the curve of A values variation occurs at inflection point. In the DMTA method time $T_{\text {flex }}$ is used to determine the coefficient of horizontal consolidation $\left(c_{h}\right)$ and the coefficient of horizontal hydraulic conductivity $\left(k_{h}\right)$ using the following formulas [7]

$$
\begin{gathered}
c_{h}=a / T_{\text {flex }}, \\
k_{h}=c_{h} \cdot \gamma_{w} / M_{h},
\end{gathered}
$$

where:

$a-$ dilatometer calibration coefficient $\left(\mathrm{cm}^{2}\right)$ for the dilatometer manufactured by Marchetti $a=7 \mathrm{~cm}^{2}$,

$T_{\text {flex }}$ - inflection time on $A$ values curve (s),

$k_{h}-$ coefficient of horizontal hydraulic conductivity $(\mathrm{cm} / \mathrm{s})$,

$\gamma_{w}-$ water unit weight $\left(\mathrm{g} / \mathrm{cm}^{3}\right)$,

$M_{h}$ - soil compressibility module (bar).

The value of $C$ is the pressure that occurs during the return of the deformed membrane of $1.1 \mathrm{~mm}$ towards the soil to the plane of the blade. In the proposed SASK method, it is assumed that the return of the deformed membrane to the position of the 
plane blades is due to pressure of the soil (soil rebound) and groundwater flowing from the fully saturated soil medium surrounding the membrane. The stream of water flow is dependent upon the deflection of the membrane geometry and time. The course of changes in water volume due to the deflection of the membrane was determined for dilatometer tests used in the spherical soil space (Fig. 2). The proposed method assumes that the water flow is at a variable pressure gradient. To calculate the hydraulic conductivity $(k)$ the following formula is proposed

$$
k=\frac{\frac{Q}{p_{1}-p_{2}}}{\frac{A t_{2}}{p_{2}}} \ln p_{1}
$$

where:

$Q \quad$ - volume of water flow equal to the volume of a section of a sphere formed from the deformed membrane $\left(\mathrm{m}^{3}\right)$,

$p_{1}, p_{2}-$ pressure, respectively the maximum needed to deform the membrane of $1.1 \mathrm{~mm}$ and the pressure at the return of the membrane to the plane of the blade $(\mathrm{hPa})$,

$l \quad-$ average range of soil involved in the flow of water $(\mathrm{m})$,

$A \quad-$ average cross-sectional area of the soil involved in the flow of water $\left(\mathrm{m}^{2}\right)$,

$t_{2} \quad-$ time of water flow; suggested $t_{2}=T_{\text {flex }}(\mathrm{sec})$.

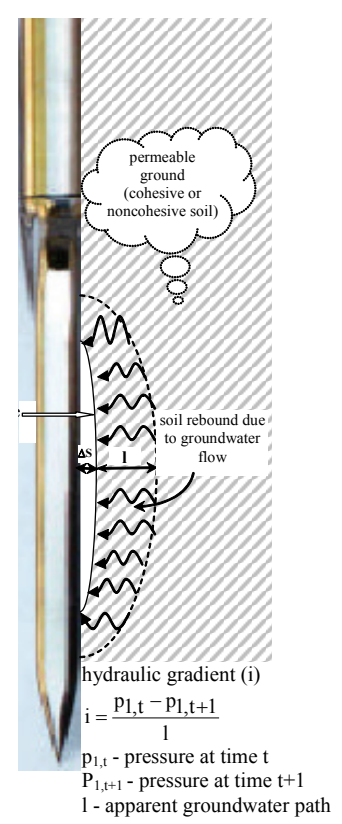

Fig. 2. Scheme of groundwater flow to DMT membrane (DMTC) 
As a result of deformation of the membrane a solid similar to the segment of a sphere is formed, whose volume can be calculated from the formula

$$
Q_{k}=\frac{\pi h^{2}}{3(3 R-h)}
$$

where:

$Q_{k}-$ volume of a sphere segment $\left(\mathrm{m}^{3}\right)$,

$h$ - deflection of the membrane $(\mathrm{m})$

$R \quad-$ radius of the sphere (m) calculated from the formula

$$
R=\frac{r^{2}-h^{2}}{2 h}
$$

$r \quad$ - radius of the membrane $(\mathrm{m})$.

The volume of water $Q$ and surface area $A$ are constants, the hydraulic gradient is variable over time, depending on depth and type of soil. Time $T_{\text {flex }}$ is taken due to adopt in order to maintain the validity of Darcy's equation. The dilatometer's membrane radius is $0.03 \mathrm{~m}$, and the hydraulic gradient $h=0.11$. Therefore, $Q_{k}=1.56^{*} 10^{-6}$ $\mathrm{m}^{3}$. The value of $A=28.27 * 10^{-4} \mathrm{~m}^{2}$ (membrane surface).

The proposed method consists of 6 steps as follows:

- Draw the plot presenting relationship between pressure $p_{c}$ and time,

- Draw a plot presenting relationship between first derivative of $p_{c}$ and time,

- Draw a plot presenting second derivative of $p_{c}$ and time,

- Read from second derivative plot $T_{\text {flex }}$ value,

- Calculate $p_{c}$ from $p_{1}$ and $p_{2}$

$$
\begin{aligned}
& p_{1}=p_{\text {flex }}-100, \\
& p_{2}=p_{\text {flex }}+100,
\end{aligned}
$$

- Calculate $k$ from the proposed equation.

In the SASK method it is recommended to carry out measurements of $C$ that do not cause distortion of the essential tests in identifying pressures $p_{1}$ and $p_{2}$. Values of $A$ can also be applied, however this can cause many errors in determining $k$ value of hydraulic conductivity.

\section{CHARACTERISTICS OF THE STUDY AREA}

Stegny plot is located in the southern part of Warsaw, in Mokotów district, in Stegny residential neighborhood. This area is on the River Vistula terrace. Location of the terrace is $5-10$ meters above the mean water level in the river. Soils which occur in the substrate are miopliocene clays [1], [3]. 
Miopliocene clays are represented mainly by the complex of clayey soils, with subordinate amounts of silty soils of limnitic origin. In the vertical profile of the clays a few sedimentation cycles, from sands to clays, were observed. The whole complex of Pliocene clays comprises: clays, silty clays (60-70\%), silts (10-25\%), sands (10-20\%).

The mineral comparison of the clays consists primarily of clay minerals and quartz, with subordinate feldspars and micas, as well as siderite, pyrite, gypsum, marcasite, goethite and hematite. The $\mathrm{CaCO}_{3}$ and organic matter content do not exceed $5 \%$ and $1 \%$, respectively. Among the clay minerals, mainly mixed-layer minerals of the beidellite-illite and kaolinite series are encountered. The basic properties of the Miopliocene clays depend on the clay fraction content: thus, the parameters of the Stegny clays are closely similar to those of clays from other parts of Warsaw. Their natural water content is almost equal to the total, and the degree of saturation is $>0.95$. The range of the values and means of each parameter are as follows [1], [3]:

- natural water content $19.2-35.6 \%, 27.6 \%$ on average;

- liquid limit $37.5-96.4 \%, 69.5 \%$ on average;

- plastic limit $22.5-41.0 \%, 30.5 \%$ on average;

- plasticity index $19.4-58.0 \%, 38.9 \%$ on average;

- liquidity index from -0.27 to $-0.24,-0.09$ on average;

- activity $0.39-1.27,0.7$ on average;

- degree of saturation $>0.95$;

Within the Stegny plot 10 Marchetti dilatometer soundings were carried out to a maximum depth of $18.2 \mathrm{~m}$. Measurements were taken at $0.2 \mathrm{~m}$ intervals, in accordance with the recommendations contained in the methodology developed by Marchetti [6]. After reading the values of $A, B, C$ obtained from dilatometer measurements of pressures $p_{0}, p_{1}, p_{2}$ were calculated. Then, after obtaining the $p_{0}, p_{1}$, and calculating the value of the effective vertical stress $\sigma_{v o}^{\prime}$ the DMT parameters $I_{D}, K_{D}, E_{D}$ and $U_{D}$ were defined.

In addition to the previous dilatometer tests carried out on Stegny plot three profiles DMTA and DMTC tests were made. An example of DMT test results for clay soils on Stegny site is presented in Fig. 3.

The results were used to determine the hydraulic conductivity according to the proposed method at a depth of $6 \mathrm{~m}$. The particle size distribution of Stegny clay at this depth is shown in Fig. 4. Clay at this depth was characterized by the parameters:

- natural moisture content $w_{n}=26.03 \%$,

- plastic limit $w_{p}=25.89 \%$,

- liquid limit $w_{1}=78.38 \%$,

- plasticity index $I_{p}=52.49$.

Based on the $p_{c}$ measurements dissipation of DMTC pressures and the second derivative of DMTC are calculated and shown in Fig. 5. To calculate hydraulic conductivity using SASK method the following data were assumed: $Q=1.56^{*} 10^{-6} \mathrm{~m}^{3} ; p_{1}, p_{2}$ 
$=1150.950 \mathrm{hPa}$, respectively; $A=28.27 * 10^{-4} \mathrm{~m}^{2} ; t_{2}=t_{\text {flex }}=2100 \mathrm{sec}$. The hydraulic conductivity of Stegny clays obtained using SASK method $\left(k=5.47 * 10^{-11} \mathrm{~m} / \mathrm{s}\right)$ was compared with previous tests results using BAT and DMTA methods as well as those obtained in laboratory (Fig. 6).
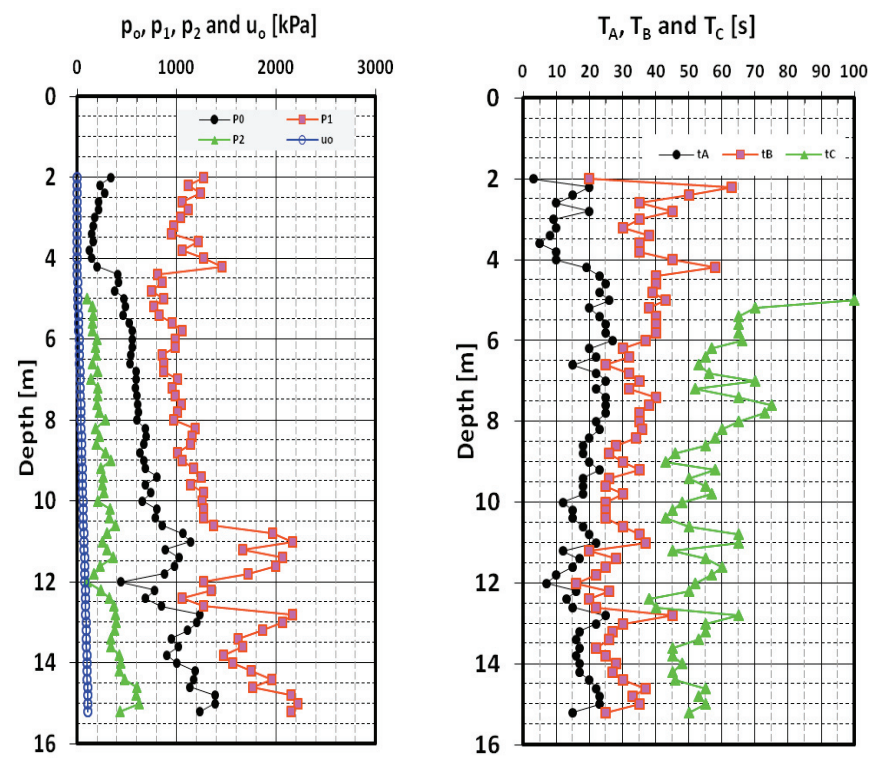

Fig. 3. DMT test results for clay at Stegny site

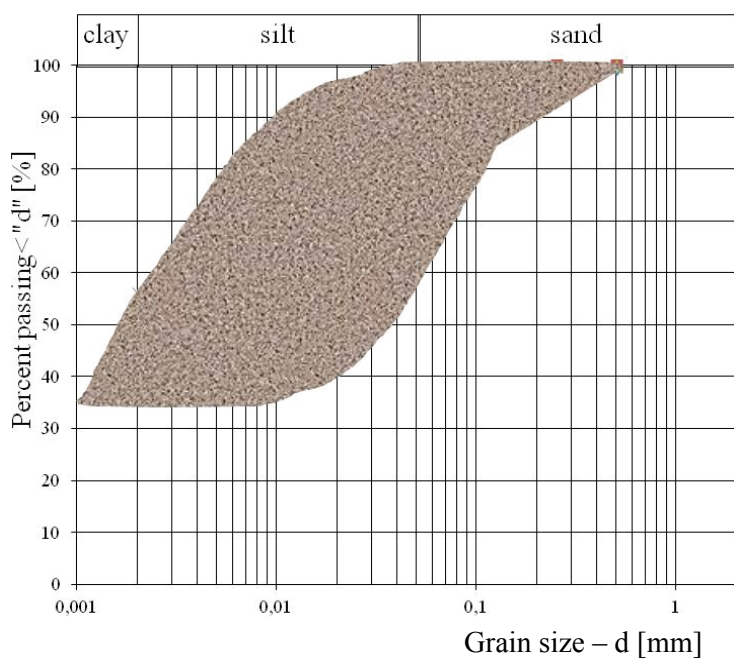

Fig. 4. Particle size distribution of Stegny clay 
a)

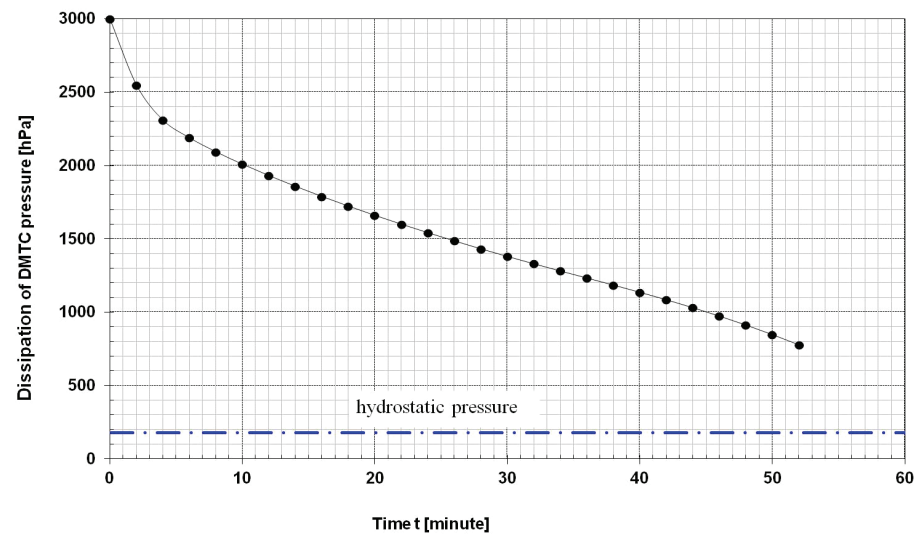

b)

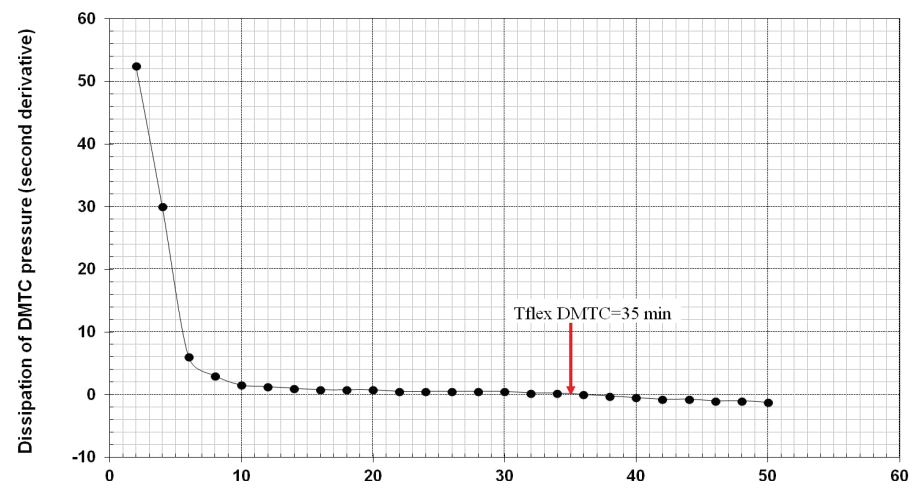

Fig. 5. DMTC test results at depth of $6.0 \mathrm{~m}$ - Stegny clay:

a) $C$ reading dissipation; b) second derivative of $C$ reading dissipation

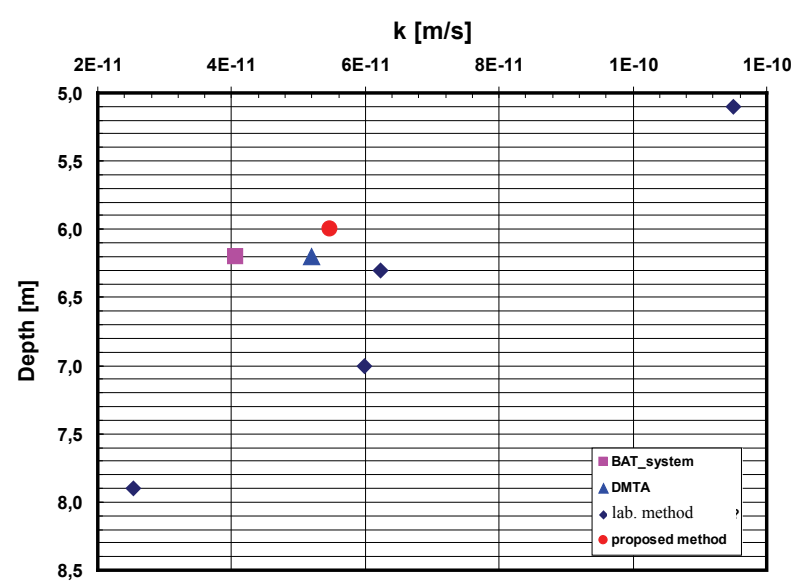

Fig. 6. Comparison of hydraulic conductivity for Stegny clays 


\section{CONCLUSIONS}

This paper presents a method of determining soil hydraulic permeability measurements using flat dilatometer (DMT). The basic idea of the method is that the return of the deformed membrane is by soil and water pressure (expansion of the porous medium and simultaneous filtration of water). To calculate the volume of flowing water the influence of the membrane in the zone designated by the three values of ground displacement was taken into account. The method was adopted in accordance with the Darcy law including a variable hydraulic gradient. The calculations assume time corresponding to the value of $t_{\text {flex }}$ (the inflexion point of the pressure dissipation curve $C$ ). Experimental results confirmed the correctness of the calculations for the clays occurring at the Stegny site. The major conclusions of the calculations and research include:

- The proposed method allows us to determine a reliable value for the permeability coefficient of clay soils. Using this method, the value of permeability coefficient is similar to the results of BAT, DMTA and laboratory tests;

- In this method, it is recommended that the hydraulic gradient should be defined for time $t_{\text {flex }}$ obtained from the curve of $C$ values. It is considered that the previous method is inappropriate and affects the basic geotechnical investigations;

- In the proposed method, it is recommend to adopt the maximum permissible differential pressure $p_{1}$ and $p_{2}$ as $200 \mathrm{kPa}$.

The proposed method was examined for a single case of clay soil at the depth of 6.2 meters to obtain reliable results. However, before prevalence, there is a need of further validation.

\section{ACKNOWLEDGEMENT}

This research was supported by two Grants No. N N506 432436 and N N506 218039 from the Ministry of Science and Higher Education, Warsaw, Poland.

\section{REFERENCES}

[1] Barański M., KaczyŃski R., BorowcZyK M., KrauŻlis K., TrZciński J., WóJCik E., Granacki W., SZCZEPAŃSKI T., ZAWRZYKRAJ P., Ocena zachowania się iłów plioceńskich ze Stegien $w$ warunkach naprężeń efektywnych, Sprawozdanie z projektu badawczego KBN Nr 5T12B 041 22. Archiwum Wydziału Geologii, 2004.

[2] Garbulewski K., Rabarijoely S., JabŁonowski S., Bayesian approach in interpretation of CPT/DMT tests, Proc. of the 11th Baltic Sea Geotechnical Conference, Geotechnics in Maritime Engineering, Gdańsk, Poland, 2008, 391-398.

[3] KaczyŃski R., Grabowska-Olszewska B., Borowczyk M., RuszczyńsKa-Szenajch H., KrAUZLIS K., TrZCIŃSKi J., BARAŃSKi M., GAWRIUCZENKOW I., WóJCIK E., Litogeneza, mikrostruktury i geologiczno-inżynierskie właściwości iłów plioceńskich rejonu Warszawy, Projekt KBN Nr 9T12B 005 16. Arch. ZPG, 2000. 
[4] Lechowicz Z., RABARIJOely S., Dilatometer C-reading to help determine stratigraphy of organic subsoil, Annals of Warsaw Agricultural Ann. Warsaw Agrcul. Univ. - SGGW, Land Reclam., 2000, 71-78.

[5] Lutenegger A., Current status of the Marchetti dilatometer test, Proc. Int. Symp. on penetration testing ISOPT-1, Orlando, 1988, 1, 137-155.

[6] Marchetti S., In Situ Tests by Flat Dilatometer, J. Geotech. Eng. Div., ASCE, 106, GT3: 299-321, 1980.

[7] Marchetti S., Totani G., Ch evaluations from DMTA dissipation curves, Proc. 9th Int. Conf. on Soil Mech. and Foun. Eng., Rio de Janeiro, 1989, Vol. 1, 281-286.

[8] MŁynareK Z., SZYMAŃSKi A., Badania in situ i ich wykorzystanie w projektowaniu, Referat generalny, Mat. X Kraj. Konf. Mech. Grunt. i Fund., Warszawa, 1993.

[9] Rabarijoely S., Garbulewski K., Rajtar J., JabŁonowski S., Geotechnical mapping of the $S G G W$ Campus in Warsaw applying the Bayesian approach, XV European Conference on Soil Mechanics and Geotechnical Engineering (ECSMGE 2011), Athens, Greece, Part 1, 2011, 447-452.

[10] Robertson P.K., Campanella R.G., Gillespie D., Excess Pore Pressures and the Flat Dilatometer Test, Proceedings, International Symposium on Penetration Testing, J.D. Ruiter (ed), A.A. Balkema, Rotterdam, The Netherlands, 1988, Vol. 2, 567-576. 